This is the author's version of a work that was published in the following source:

Kazhamiaka, F.; Jochem, P.; Keshav, S.; Rosenberg, C. (2017).

On the Influence of Jurisdiction on the Profitability of Residential PhotovoltaicStorage Systems : A Multi-National Case Study.

Energy policy, 109, 428-440. doi:10.1016/j.enpol.2017.07.019

Please note: Copyright is owned by the author(s) and / or the publisher. The commercial use of this copy is not allowed. 


\title{
On the Influence of Jurisdiction on the Profitability of Residential Photovoltaic-Storage Systems: A Multi-National Case Study
}

\author{
Fiodar Kazhamiaka*a , Patrick Jochem $^{b}$, Srinivasan Keshav ${ }^{a}$, Catherine Rosenberg ${ }^{c}$ \\ ${ }^{a}$ University of Waterloo, Cheriton School of Computer Science, 200 University Ave. West, Waterloo, Ontario, Canada \\ ${ }^{b}$ Karlsrube Institute of Technology (KIT), Institute for Industrial Production (IIP), Kaiserstr. 12, D-76133 Karlsruhe, Germany \\ ${ }^{c}$ University of Waterloo, Electrical and Computer Engineering, 200 University Ave. West, Waterloo, Ontario, Canada
}

\begin{abstract}
Policy makers in many jurisdictions have implemented incentive schemes such as 'feed-in tariffs' (FIT) and upfront purchase subsidies to encourage consumers to self-generate parts of their power requirements by solar energy. We quantitatively study the impact of jurisdiction-specific solar radiation profile, the typical residential loads, the cost of system components, the price of grid electricity, and incentive programs on photovoltaic (PV) and storage system profitability in Germany, Ontario, and Austin, Texas. In each jurisdiction, for a range of PV and storage system sizes, we compute the optimal use of the system, and hence the best possible profitability of that system in that jurisdiction over a 20 year life span. This methodology allows us to quantitatively estimate the influence of a jurisdiction on the (best possible) profitability of PV-storage systems. We find that the choice of jurisdiction has significant impact on the profitability of PV-storage systems. We also find that policy makers can use the price of grid electricity as well as upfront subsidies to influence profitability, and therefore adoption.
\end{abstract}

\section{KEYWORDS}

Residential PV System, Residential Storage System, Economic Analysis

\section{INTRODUCTION}

The rapid decline in the prices of solar photovoltaic (PV) systems and energy storage solutions has made it possible for residential electricity customers to weaken their ties to the local distribution grid by self-generating some parts of their power requirements $[13,49]$. This has many potential benefits, including the substitution of clean solar power for dirty fossil fuels, a reduction in distribution losses, reduced investments in additional centralized generation facilities to accommodate demand growth, and enhanced grid resilience in case of natural disasters. For these reasons, policy makers in many jurisdictions have implemented incentive schemes such as 'feed-in tariffs' (FIT) and upfront purchase subsidies to encourage consumers to become 'prosumers' (i.e., energy producers as well as consumers).

Despite these incentives, other than with a few notable exceptions, residential PV adoption, and certainly residential storage adoption, has not been widespread. Interestingly, this is despite the adoption of nearly identical policies in different jurisdictions. For example, residential solar has been heavily adopted in Southern Germany, very likely due to its FIT program, but is quite rare in Ontario, despite the deployment of a similar FIT program there. A natural question is to ask why the same program is successful in one jurisdiction but not in another. Generalizing from this question, from the perspective of a policy maker, one would wish to know what policy actions are best suited to encourage PV and storage system adoption in a particular jurisdiction. Similarly, from the perspective of a vendor of PV and storage systems, understanding the influence of jurisdiction on system adoption would help selecting which market to penetrate, rather than to adopt a scattershot approach. Thus, the focus of our work is to understand the influence of jurisdiction on the profitability - and thus adoption ${ }^{1}$ - of residential PV and storage systems.

From previous jurisdiction-specific profitability analyses (see Section 2) and our own understanding, we define the parameters that characterize a jurisdiction to be: its typical solar radiation profile, the typical residential loads, the cost of system components, the price of grid electricity, and incentive programs (note that some of these parameters are not under the

\footnotetext{
${ }^{1}$ System profitability and adoption are tightly correlated [7]
} 
control of the policy makers and some are). To study the impact of these factors, we use three case studies, determining parameter values for the jurisdictions of Germany, Ontario, and Austin, Texas. In each jurisdiction, for a range of PV and storage system sizes, we compute the optimal use of the system, and hence the best possible profitability of that system in that jurisdiction over a 20 year life span (similar to $[8,21]$ ). This methodology allows us to quantitatively estimate the influence of a jurisdiction on the (best possible) profitability of PV-storage systems. Importantly, we account for anticipated changes in future grid electricity prices, as well as the need to replace the storage system after 10 years of use. Our approach also lets us make jurisdiction-specific policy recommendations to encourage PV-storage system adoption.

We find that policy makers can use the price of grid electricity as well as upfront subsidies to influence profitability, and therefore adoption. We also find that the choice of jurisdiction has significant impact on the profitability of PV-storage systems, even when the same policy is used. For example, we find that in Germany and Austin jurisdictions, the characteristics of the magnitude and structure of electricity prices as well as residential loads contribute to differences in PV-storage system profitability despite having a comparable tariff for PV generation that is sold to the grid; furthermore, the price-point at which batteries become a profitable investment is significantly different for these two jurisdictions. However, when the FIT price is high, there is no incentive to adopt storage, as is the case in Ontario today.

Our key contributions are:

- Determining the set of parameters that characterize a jurisdiction, from the perspective of residential PV-storage system adoption,

- Using this characterization to create an evaluation methodology to estimate the return on investment and profitability of a PV-storage system of a given size in a given jurisdiction,

- Applying our methodology in a data-driven study to give policy recommendations for three jurisdictions: Germany, Ontario, and Austin, Texas, and

- A public release of our optimization model implementation [14] in AMPL [15].

The remainder of the paper is laid out as follows. Section 2 discusses prior work on the topic of PV-storage systems. Section 3 describes our methodology for calculating the profitability of deploying PV-storage systems, as well as the core differences between the jurisdictions which affect the calculation. Section 4 describes the data that we use as input for our profitability calculations. In Section 5 we present the profitability results and policy recommendations. We conclude the paper in Section 6.

\section{BACKGROUND AND RELATED WORK}

There is a fast developing literature on the deployment of storage in combination with residential roof-top PV systems (e.g. [29,30]). Some research focuses on the operation of these systems (e.g. [26,38]), while others focus on system sizing (e.g. [11,13]). Researchers have compared different local storage technologies (e.g. [42]) as well as the impact of different electricity tariffs (e.g. [39]) and some analysis shows that profitable operations is already possible for commercial buildings [31]. In the future, stationary storage (not necessarily Li-Ion) might be even profitable by outbalancing the electricity demand during dynamic tariffs alone [18]. Besides the focus on residential PV-storage systems, storage-alone systems have also been analyzed; e.g. Dufo-López [11] shows that arbitrage with hypothetical dynamic tariffs in Spain would be sufficient to make decentralized storage profitable.

Most studies focus on a single jurisdiction. For example, Linssen et al. [27], Weninger et al. [47], and Johann \& Madlener [20] focused on Germany, Lorenzi \& Santos Silva [28] on Portugal, Yoshida et al. [50] on Japan, de Oliveira e Silva \& Hendrick [10] on Belgium, Telaretti et al. [42] on Italy, Parra \& Patel [35] on Switzerland as well as Nicholls et al. [33], Ratnam et al. [38], and Ren et al. [39] on Australia. Only a few studies compare different jurisdictions; e.g. Quoilin et al. [36] 
compare the application of PV-storage systems in several European jurisdictions, Zucker \& Hinchliffe [52] focus on Italy and Germany, and Bertsch et al. [8] focus on Ireland and Germany. These studies have found that not all jurisdictions allow a profitable operation of PV-storage systems. However, the results depend strongly on the assumed electricity tariffs, battery prices, battery life time, household load patterns, etc. Moreover, rapidly decreasing battery prices make future increased profitability in most jurisdictions probable. Consequentially, our work focuses on the core parameters that influence the profitability of PV-storage systems in domestic households, which are described in detail in Section 3.2, in three different jurisdictions: Germany, Southern Ontario, and Austin, Texas.

More recent literature includes also electric vehicles into considerations. For example, Kaschub et al. [21] have carried out a comprehensive analysis of the profitability of PV-storage systems in German households including time-dependent electricity demand from electric vehicles as well as battery degradation similar to [50]. Their model approach is similar to ours, however, they focus on the synergies between stationary storage and electric vehicles and do not compare different jurisdictions. They find that while the charging of the electric vehicles increases domestic electricity demand and therefore increases the profitability of the system, enabling the EV to feed electricity back to the grid (V2G) competes with the battery and leads to a decreasing net present value (NPV) of the batteries. The underlying optimization problem is a MILP, which optimizes system configurations and operation of the PV-battery systems for empirical PV and household load data over 20 years. The authors identify a positive NPV of installations after 2018 for most German households considered.

\section{METHODOLOGY}

\subsection{System Model and Problem Formulation}

The system of interest is a PV-storage system that is composed of a set of PV panels (called the PV module in the following) and a Lithium-ion battery located in a private household. The homeowner is assumed to have some inflexible intrinsic load. This load must be met using a combination of the power produced and stored by the PV-storage system as well as from the main electrical grid. Our goal is to compute the benefit to a home-owner of investing in such a residential PV-storage system.

The initial capital expenditure on the PV-storage system is offset by a reduction in payments to the utility, and, in some jurisdictions, the sale of excess generation to the utility (i.e. if there is a feed-in tariff). Given a particular system sizing, i.e. peak power output from the solar panel and the energy capacity of the storage, we compute the optimal operation of the system (i.e. scheduling the battery charging and discharging process) using an optimization problem expressed as an integer linear program (ILP). Our optimization objective is to maximize the 20 year return on investment (ROI), where the investment comprises the system capital expense in the initial year (i.e. 2016) added to recurring operating expenses ${ }^{2}$ over the lifetime of the system (in constant prices). A positive ROI implies a profitable investment, which can be directly compared to the rates of return from alternative investment vehicles (see Section 5). The ROI is defined as follows:

$$
\mathrm{ROI}=\frac{\text { PayNS }- \text { PayS }+ \text { Rev }- \text { Investment }}{\text { Investment }}
$$

Equation 1.

where PayNS is the total payment to the grid for meeting the load in a scenario with no system. PayS is the remaining payment to the grid with the system and Rev is the revenue from selling energy (from the PV system) to the grid. Investment is the cost of the system over its lifetime, i.e., PV panel, Lithium-ion battery, inverter, and associated installation and maintenance costs. The profit of the system over 20 years is the numerator of the right-hand-side of Equation 1., i.e., Profit $=$ PayNS - PayS + Rev - Investment .

We now discuss the system model in more detail. Figure 1 illustrates the sources and destinations of the power flows in the system. Power is introduced into the system from two sources: the solar PV module and the grid. The power output of a panel with $1 \mathrm{~kW}$ capacity is denoted $P_{S}$ and is multiplied by the installed capacity $P V$ to get the total production of the installed panels. The power flowing from the electrical grid is denoted $P_{g}$. Power is consumed by the local load, denoted as

\footnotetext{
${ }^{2}$ While there are many recurring costs, we only take into account the replacement of the battery, which is the dominant recurring cost over the lifetime of the system.
} 


\begin{tabular}{clc} 
Name & Description (units) & Time-dependent \\
\hline System parameters and variables & $\checkmark$ \\
$P_{S}$ & Power generated by solar panels (kW) & $\checkmark$ \\
$P_{L}$ & Electrical load of household (kW) & \\
$B$ & Rated energy capacity of the battery (kWh) & \\
$P V$ & Installed PV panel generation capacity (kW) & \\
$B_{\text {max }}$ & Maximum battery energy capacity that can be installed (kWh) & \\
$P V_{\text {max }}$ & Maximum PV panel generation capacity that can be installed (kW) & \\
$a_{1}, a_{2}$ & Battery maximum discharge and charge fractions & \\
$\alpha_{c}\left(\alpha_{d}\right)$ & Charge (discharge) rate limits per unit of storage (kW/kWh) & $\checkmark$ \\
$\eta_{c}\left(\eta_{d}\right)$ & Charge (discharge) efficiency. Both are $\leq 1$ & $\checkmark$ \\
$P_{g}$ & Power drawn from the grid (kW) & $\checkmark$ \\
$P_{\text {sell }}$ & Power sold to the grid (kW) & $\checkmark$ \\
$P_{c h}$ & Power used to charge the battery (kW) & $\checkmark$ \\
$P_{d i r}$ & Power flowing directly from PV and grid to meet the load or be sold $(\mathrm{kW})$ & $\checkmark$ \\
$P_{d i s}$ & Power drawn from the battery (kW) & \\
$E_{b}$ & Energy content of the battery (kWh) & \\
$U$ & Initial energy content of the battery (kWh) & \\
$T_{u}$ & Time slot duration (hours) & \\
$K$ & Number of time slots in one year & \\
$Y$ & Number of years in the time horizon being considered & \\
Pricing & & \\
\hline$\pi_{F I T}$ & Price per unit of energy sold $(\$ / \mathrm{kWh})$ & \\
$\pi_{g}$ & Price per unit of energy purchased in Germany $(\$ / \mathrm{kWh})$ & \\
$p$ & Price per unit of energy purchased in Ontario (varies over time) $(\$ / \mathrm{kWh})$ & \\
$p_{j}$ & Price per unit of energy purchased in tier $j$ in Austin, Texas $(\$ / \mathrm{kWh})$ & \\
$z$ & Price multiplier, multiplied by initial grid price to give the price expected in & \\
$i$ & each year of the time horizon & \\
$i$ & Annual inflation rate & \\
\hline
\end{tabular}

Table 1. Notation

$P_{L}$, or sold to the grid, denoted as $P_{\text {sell }}$. The consumers can receive their power directly from the sources, with this flow denoted $P_{d i r}$, or from the lithium-ion battery with energy content denoted $E_{b}$. Power used to charge the battery is denoted $P_{c h}$, and power discharged from the battery is denoted $P_{d i s}$. We define power flows over discrete time slots of equal duration $T_{u}$, and use two indices to indicate time: $k$ is the time slot in year $y$, with $K$ time slots in one year, and $Y$ years in the time horizon being considered. The following constraints ensure the conservation of power and that the load is met:

$$
\begin{array}{r}
P_{g}(k, y), P_{\text {dir }}(k, y), P_{\text {sell }}(k, y) \geq 0 \\
P V \cdot P_{S}(k, y)+P_{g}(k, y) \geq P_{\text {dir }}(k, y)+P_{c h}(k, y) \\
P_{\text {dir }}(k, y)+P_{\text {dis }}(k, y)=P_{\text {sell }}(k, y)+P_{L}(k, y)
\end{array}
$$

Equation 2.

Equation 3.

Equation 4.

The battery has a capacity $B$, and upper and lower energy content limits denoted $a_{1}$ and $a_{2}$ which are fractions of $B$. Charging and discharging efficiency parameters $(\leq 0)$ are denoted $\eta_{c}$ and $\eta_{d}$ respectively. Limits of charging and discharging power scale with $B$ are denoted as $\alpha_{c}$ and $\alpha_{d}$ respectively. The battery cannot be charged and discharged simultaneously; 


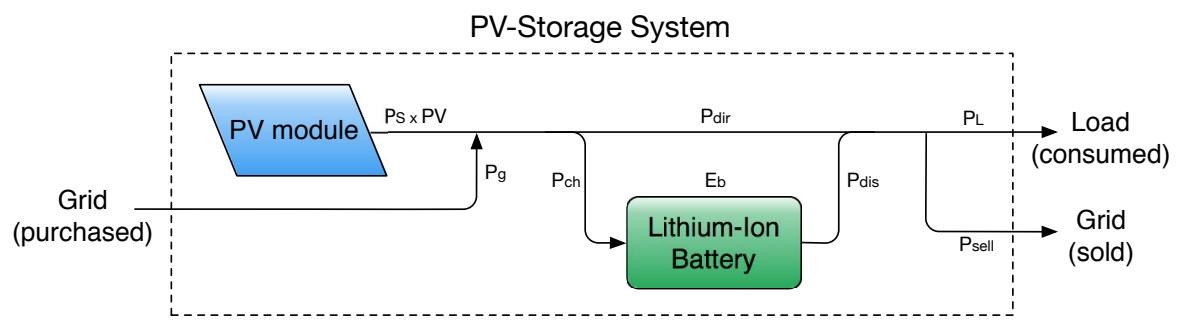

Figure 1. System diagram, with labels for power flows.

this is enforced using a binary indicator variable $I(k)$. These battery constraints are expressed below.

$$
\begin{array}{r}
0 \leq P_{c h}(k, y) \leq I(k, y) B \alpha_{c} \quad \forall k \in[1 . . K] \\
0 \leq P_{d i s}(k, y) \leq(1-I(k, y)) B \alpha_{d} \quad \forall k \in[1 . . K], y \in[1 . . Y] \\
P_{\text {sell }}(k, y) \leq P_{s}(k, y) P V \\
E_{b}(0,1)=U \\
E_{b}(k, y)=E_{b}(k-1, y)+\eta_{c} P_{c h}(k, y) T_{u}-\frac{P_{d i s}(k, y)}{\eta_{d}} T_{u} \quad \forall k \in[1 . . K], y \in[1 . . Y] \\
E_{b}(0, y)=E_{b}(K-1, y-1) \quad \forall y \in[2, Y] \\
B a_{1} \leq E_{b}(k, y) \leq B a_{2} \quad \forall k \in[1 . . K], y \in[1 . . Y]
\end{array}
$$

Equation 5.

Equation 6.

Equation 7.

Equation 8.

Equation 9.

Equation 10.

Equation 11.

Equation 5. and Equation 6. constrain the charging and discharging power and ensure that the battery is not charged and discharged simultaneously. Equation 7. constrains the system to selling only locally generated PV power. Equation 8. initializes the energy content of the battery to a given value $U$, Equation 9. defines how the energy content changes as a function of the charging and discharging power, and Equation 10. ensures smoothness between years. A detailed description and evaluation of the battery model we use can be found in Reference [23].

The ILP that optimizes the operation of a given system over its lifetime to maximize the ROI, referred to as $P_{1}$, is as follows. Given $\left(P_{S}(k, y)\right)$, the complete data set of the PV output during the lifetime of the system, $\left(P_{L}(k, y)\right)$, the complete data set of the home load during the lifetime of the system, $\alpha_{c}, \alpha_{d}, \eta_{c}, \eta_{d}, a_{1}, a_{2}, B, P V, U, T_{u}$ :

$$
P_{1}: \quad \max _{\substack{\left(P_{g}(k, y)\right),\left(P_{\text {sell }}(k, y)\right),\left(P_{\text {ch }}(k, y)\right) \\\left(P_{\text {dis }}(k, y)\right),\left(P_{\text {dir }}(k, y)\right)}} \text { ROI }
$$

subject to: Equation 2.-Equation 11.

Equation 12.

The ILP that optimizes the operation of a given system over its lifetime to maximize the Profit with the battery and PV panel sizes as variables, referred to as $P_{2}$, is as follows. Given $\left(P_{S}(k, y)\right),\left(P_{L}(k, y)\right), \alpha_{c}, \alpha_{d}, \eta_{c}, \eta_{d}, a_{1}, a_{2}, U, T_{u}$ :

$$
\begin{aligned}
& P_{2}: \quad \max _{\substack{\left(P_{g}(k, y)\right),\left(P_{\text {sell }}(k, y)\right),\left(P_{c h}(k, y)\right),\left(P_{\text {dis }}(k, y)\right),\left(P_{\text {dir }}(k, y)\right), B, P V}} \text { Profit } \\
& \text { subject to: Equation 2.-Equation } 11 . \\
& 0 \leq P V \leq P V_{\max } \\
& 0 \leq B \leq B_{\max }
\end{aligned}
$$

where $P V_{\max }$ and $B_{\max }$ are the maximum PV capacity (in $\mathrm{kW}$ ) and battery capacity (in $\mathrm{kWh}$ ) that can be installed.

To keep the analysis tractable, system dimensions are an input to the ILP, which emits the ROI. We then compute the ROI for a plausible range of dimension parameters, which allows us to compute the ROI as a function of the system dimensions. 
Note that calculating the ROI and Profit requires us to model the time-evolution of the price of grid power as well as the FIT rate. These differ in each jurisdiction, and are described in the next subsection.

\subsection{Jurisdictions}

In this work we consider three jurisdictions for deploying a PV-storage system: 1) Germany, 2) Southern Ontario, Canada, 3) The city of Austin, Texas, USA. There are many differences between these jurisdictions that can play a role on the profitability of PV-Storage systems; in our model, we focus on the following jurisdictional differences:

PV production: The intensity of solar radiation depends on the location of the jurisdiction on the globe as well as the local cloud patterns. As a result, some jurisdictions benefit more from PV panel installations than others.

PV market maturity: The cost of installing PV panels differs significantly between jurisdictions.

Storage cost: It was relatively difficult to find information about storage cost in the literature but Tesla reports comparable prices for their Powerwall battery [43] in the three jurisdictions being considered.

Electrical load: The amount of electricity consumed by a household is dependent on the local habits, climate and number of electrical appliances. Air conditioners and electric heaters are examples of appliances with high consumption profiles that depend significantly on the climate, insulation of the houses, and heating devices.

Grid pricing: The household electricity bill is dependent on the pricing scheme that is decided by the electrical utility provider. A pricing scheme is a set of rules for determining the price of electricity. In some jurisdictions the pricing scheme and price of electricity is regulated and only a single tariff is offered to all customers; other jurisdictions have utilities that offer a large selection of pricing schemes. To calculate the 20 year ROI of a residential PV-battery system, we assume that the grid prices will evolve following the linear trends observed over the last 10 years in each jurisdiction (as shown in Figure 2). We model the price evolution by using a multiplier $z(y)$ (a different one in each jurisdiction) that, when multiplied by the grid prices seen in 2016, gives us the grid price that we would see in year $y$.

Feed-in Tariff: The FIT is the price per kWh of energy that is earned for selling solar power. The FIT is usually a flat rate, denoted $\pi_{F I T}$. In our model we take into account the effect of annual inflation, denoted $i$, on the value of the FIT rate assuming no change in policy.

Incentives: Some jurisdictions have incentive programs to lower the cost of installing PV panels or battery systems. For example, in the United States there is a federal tax credit for homeowners who install PV panels [44], and in Sweden there is a subsidy that covers up to $60 \%$ of the costs of home energy storage systems [48].

Next, we describe each jurisdiction and how to calculate jurisdiction-specific ROI. Parameters that are specific to Germany, Southern Ontario, or Austin are identified by the subscript ge, so, or au respectively. 


\subsubsection{Germany}

Germany receives around $1000-1200 \mathrm{kWh} / \mathrm{m}^{2}$ solar global horizontal radiation $(\mathrm{GHI})^{3}$ annually. Compared to the other two jurisdictions, German residential electricity demand is rather low mainly due to good insulation of houses and low share of electricity-based heating and cooling devices. Furthermore, the high electricity price incentivizes energy-saving behaviour and an absence of energy-intensive appliances such as outdoor hot tubs, air conditioners, huge refrigerators or electric heating systems.

Most residents pay a flat price, denoted as $\pi_{g}$, for their electricity demand plus a (consumption independent) monthly base fee. All households can choose their electricity provider among several dozen of competing providers. The constant FIT is provided by the federal government and is specified in a contract that lasts 20 years. Consequently, the relevant terms from the household perspective in the ROI calculation are as follows:

$$
\begin{aligned}
\operatorname{PayN}_{g e} & =\sum_{y=1}^{Y} \sum_{k=1}^{K} z(y) \pi_{g} P_{L}(k, y) T_{u} \\
\text { Pay }_{g e} & =\sum_{y=1}^{Y} \sum_{k=1}^{K} z(y) \pi_{g} P_{g}(k, y) T_{u} \\
\operatorname{Rev}_{g e} & =\sum_{y=1}^{Y} \sum_{k=1}^{K} \frac{\pi_{F I T} P_{\text {sell }}(k, y) T_{u}}{(1+i)^{y}}
\end{aligned}
$$

Equation 16.

Equation 17.

Equation 18.

Note that, since prices are in $\$ / \mathrm{kWh}$, the time slot length $T_{u}$ is needed in the equations to convert the power consumption in a time slot into a corresponding energy value.

In addition to analyzing the profitability of PV-storage systems in Germany under a flat grid pricing scheme, we explore the effect of introducing two time-of-use (ToU) pricing schemes. ToU tariffs are currently unusual in Germany, but highly probable in the near future $[19,25]$. One of the primary goals of a ToU scheme is to provide a price incentive for load shifting, which can be done by using electrical appliances during off-peak price periods, or by using a battery. We assume two simple tariffs, which have a day period $(8 \mathrm{am}-8 \mathrm{pm})$ and a night period $(8 \mathrm{pm}-8 \mathrm{am})$. One ToU scheme has high prices during the day and low prices at night, which follows consumer demand patterns that are typically higher during the day (cf. Ontario). The second ToU scheme has low prices during the day and high prices at night, representing an incentive to use electricity when solar energy penetration is high and electricity market spot prices are consequently low. Details on how we assign the prices for these schemes are given in Section 4.3.

\subsubsection{Southern Ontario}

Southern Ontario receives around $1300-1400 \mathrm{kWh} / \mathrm{m}^{2}$ solar GHI annually. A typical household would be equipped with an air conditioner and natural gas heating.

The grid pricing scheme is regulated by the province of Ontario. All residential consumers of electricity are subject to a ToU pricing scheme consisting of off-peak (cheapest), mid-peak, and peak (most expensive) periods. We model the time dependence of the electricity using a parameter $p(k)$. Just like in Germany, the FIT is a constant rate guaranteed through a 20 year contract as part of the microFIT program [2] and is adjusted for inflation so that it keeps its value. The terms in the ROI calculation are as follows:

\footnotetext{
${ }^{3}$ The GHI estimates for all jurisdictions are based on SolarGIS maps from the years 1994-2013.
} 


$$
\begin{array}{r}
\operatorname{PayN}_{s o}=\sum_{y=1}^{Y} \sum_{k=1}^{K} z(y) p(k, y) P_{L}(k, y) T_{u} \\
\text { PayS }_{s o}=\sum_{y=1}^{Y} \sum_{k=1}^{K} z(y) p(k, y) P_{g}(k, y) T_{u} \\
\operatorname{Rev}_{s o}=\sum_{y=1}^{Y} \sum_{k=1}^{K} \pi_{F I T} P_{\text {sell }}(k, y) T_{u}
\end{array}
$$

Equation 19.

Equation 20.

Equation 21.

\subsubsection{Austin, Texas}

The city of Austin is located in central Texas, and receives around $1700-1800 \mathrm{kWh} / \mathrm{m}^{2}$ solar GHI annually. Given the climate, the vast majority of households are equipped with air conditioners. Austin's electricity is delivered exclusively by Austin Energy, a publicly-owned electric utility company.

The residential pricing scheme in Austin is comprised of monthly usage energy tiers, where the price of energy depends on how much energy has been consumed that month. The scheme consists of five price tiers, with low prices for energy usage that falls within tier $1(0-500 \mathrm{kWh})$ and highest for energy usage in tier $5(>2500 \mathrm{kWh})$. It is straightforward to calculate the energy bill of the user with no system $(\operatorname{PayNS})$, but describing the pricing scheme as part of a linear objective function requires additional variable and constraints. We denote the price of tier $j(j \in\{1, \ldots, 5\})$ as $p_{j}$, and the size of each tier as $\Gamma_{j}(j \in\{1, \ldots, 4\})^{4}$. To construct the objective function, we introduce new variables $x_{j}(m, y)$ 's which represent the energy consumption in tier $j$ in month $m$ of year $y$, with $M$ months in a year. Note that PayNS can be pre-calculated because it does not rely on any optimization variables and is difficult to express in one equation, hence we do not show it here; the remaining terms of the ROI calculation and the constraints necessary to ensure proper energy bill calculation are below:

$$
\begin{array}{r}
\text { Pay }_{a u}=\sum_{y=1}^{Y} \sum_{m=1}^{M} \sum_{j=1}^{5} z(y) x_{j}(m, y) p_{j} \\
0 \leq x_{j}(m, y) \leq \Gamma_{j} \forall j \\
0 \leq x_{5}(m, y) \forall m, y \\
\sum_{j=1}^{5} x_{j}(m, y)=\sum_{k \in m} P_{g}(k, y) T_{u} \forall m, y
\end{array}
$$

Equation 22.

Equation 23.

Equation 24.

Equation 25.

Equation 26.

This formulation will calculate the electricity bill for the five-tiered pricing scheme, assuming that the objective is to minimize the bill and that $p_{j}<p_{j+1}$.

The FIT provided by Austin Energy is based on a "value of solar" concept $[37,41]$ where the tariff is re-calculated annually and, unlike the FIT in Ontario and Germany, there are no long-term contracts. This tariff was introduced in 2012, and there are not enough historical tariffs of this type to suggest a trend in the change of the tariff over the next twenty years. As a simplification, we approximate the tariff as a constant price, to the same effect as the contract FIT structure seen in Germany:

\footnotetext{
${ }^{4}$ Tier 5 does not have a size restriction
} 


\begin{tabular}{c|c}
\hline Parameter & Value \\
\hline$\alpha_{c}$ & 0.52 \\
$\alpha_{d}$ & 0.52 \\
$a_{1}$ & 0 \\
$a_{2}$ & 1 \\
$\eta_{c}$ & 0.95 \\
$\eta_{d}$ & 0.95 \\
\hline
\end{tabular}

Table 2. Battery parameters

$$
\operatorname{Rev}_{a u}=\sum_{y=1}^{Y} \sum_{k=1}^{K} \frac{\pi_{F I T} P_{\text {sell }}(k, y)}{(1+i)^{y}}
$$

Equation 27.

Residents of Austin are eligible for a $30 \%$ tax credit on PV installations as part of the U.S. Residential Renewable Energy Tax Credit program [44], which lowers the effective cost of PV in this jurisdiction.

\subsection{Assumptions}

When installing PV panels and storage systems, there are some fixed costs that make small systems more expensive than large systems in terms of cost per unit of installed capacity. In our calculations, we simplify these costs by bundling PV and battery costs into respective $\$ / \mathrm{kW}$ and $\$ / \mathrm{kWh}$ values which are independent from the size of the system.

\section{DATA}

\subsection{System}

The PV-storage system is characterized by the PV generation capacity, the battery parameters, and the cost ${ }^{5}$. We consider an installed PV generation capacity of up to $10 \mathrm{~kW}$, which is a large installation that still fits on a typical residential rooftop. The battery parameters reflect the characteristics of a Tesla Powerwall 2 and are given in Table 2. We assume that the system is purchased in the year 2016. The cost of PV panels that we use is $€ 1.73$ (2.16 USD) per Watt in Germany [16], 2.68 CAD (2.26 USD) per Watt in Ontario [40], and 3.38 USD per Watt in Austin [1]. For the case of Austin, we also consider the effect of the 30\% tax incentive for PV installations, which would lower the effective PV cost to $2.37 \mathrm{USD}$. We assume that the panel has a lifetime of 20 years. The cost of the battery component is calculated to be $\$ 525 / \mathrm{kWh}$, obtained using the $\$ 6500$ battery cost and $\$ 1600$ installation cost for a $13.5 \mathrm{kWh}$ Powerwall 2. We assume a battery lifetime of 10 years, in accordance with the warranty offered by Tesla, and hence the need to replace the batteries after 10 years [43]. The battery cost is projected to drop at a rate of $5 \%$ per year to approximately $60 \%$ of the current price [34], hence the total price for the storage system for 20 years is estimated to be $\$ 840 / \mathrm{kWh}$ of storage capacity.

\subsection{PV and load traces}

We use one year of PV generation and load data traces from each jurisdiction to represent what can be expected from these jurisdictions over the next twenty years. The data representing household electrical load in Germany comes from a data set of 90 households [21] from across the country, and the PV generation is represented using measurements collected from Karlsruhe, Baden-Wurttemberg. The load data for 100 Southern Ontario households was obtained from an anonymized smart meter data set, and the PV generation data is a Toronto, Ontario trace from the NREL System Advisor Model [9] database. The load data for 105 households Austin was obtained from the Pecan Street Dataport [6], and a PV trace from

\footnotetext{
${ }^{5}$ All prices and costs are given in $U S D_{2016}$ using the following conversion rates: $1 \mathrm{CAD} \rightarrow 0.8 \mathrm{USD}, 1 \mathrm{EURO} \rightarrow 1.2 \mathrm{USD}$
} 
the same source is used to represent typical PV generation. All of the data has hourly resolution, which is sufficient for ROI and profit analysis [24].

\subsection{Pricing}

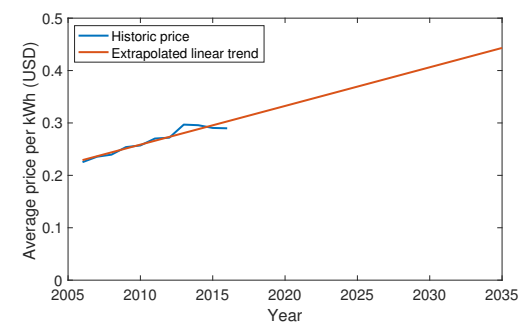

(a) Germany

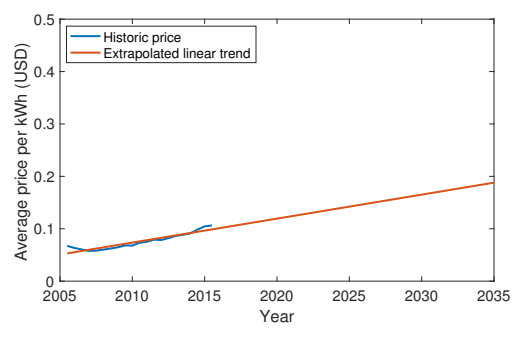

(b) Ontario

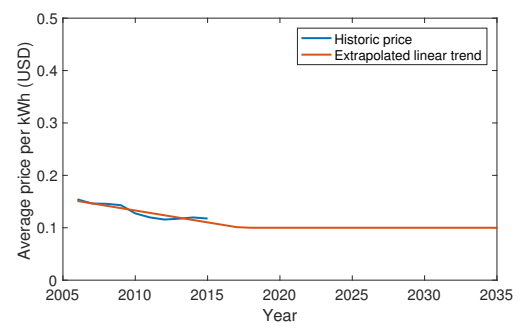

(c) Austin

Figure 2. Electricity price developments: 2005-2035.

We use prices for 2016 for each jurisdiction. In the following, the prices in USD are shown in brackets in case a conversion from local currency is needed.

In 2015, German households paid an average of $€ 0.287$ (0.344)/ $\mathrm{kWh}$ of electricity [5], and FIT contracts made in 2016 set a rate of $€ 0.1231$ (0.1477) [49]. In 2016, the per-kWh ToU rates in Ontario are 0.087, 0.132, and 0.18 CAD $(0.696,0.106,0.144$ USD) for off-peak, mid-peak, and peak periods respectively. Figure 3 shows the duration of each period on a weekday; on weekends and holidays, electricity usage is billed at the off-peak rate [3]. The FIT rate for Ontario in 2016 is $\$ 0.313$ (\$0.25) $/ \mathrm{kWh}$ for installations with up to $6 \mathrm{~kW}$ of capacity, and $\$ 0.294(\$ 0.235) / \mathrm{kWh}$ for installations with capacity between 6 $\mathrm{kW}$ and $10 \mathrm{~kW}$ [2]. The rates for the tiered pricing scheme used by Austin Energy in 2016 [1] are described in Table 3, and the FIT rate in 2016 is $\$ 0.109 / \mathrm{kWh}$ [1]. An annual inflation rate of $2 \%$ is used to affect the value of the FIT in Austin and Germany.

For the analysis of Germany under ToU pricing schemes, we chose prices to follow a 2:1 ratio of peak price to off-peak price which is similar to the ratio in Ontario's ToU scheme. For one ToU scenario, the day prices are set to $\$ 0.44 / \mathrm{kWh}$ and night prices at $\$ 0.22 / \mathrm{kWh}$; the other ToU scenario has day prices at $\$ 0.24$ and night prices at $\$ 0.48$. The prices were chosen such that the consumer's grid payments would, on average, be approximately what they are under the flat pricing scheme with a rate of $\$ 0.344 / \mathrm{kWh}$, i.e. the utility company would earn the same amount of money from customers that do not purchase a PV-storage system as they would with the flat pricing scheme.

Future prices are modeled by calculating the slope of the best least-squares linear fit of historical prices between 2006 and 2016, and using the slope of the linear fit to predict the development of prices for the next 20 years. For Ontario and Austin

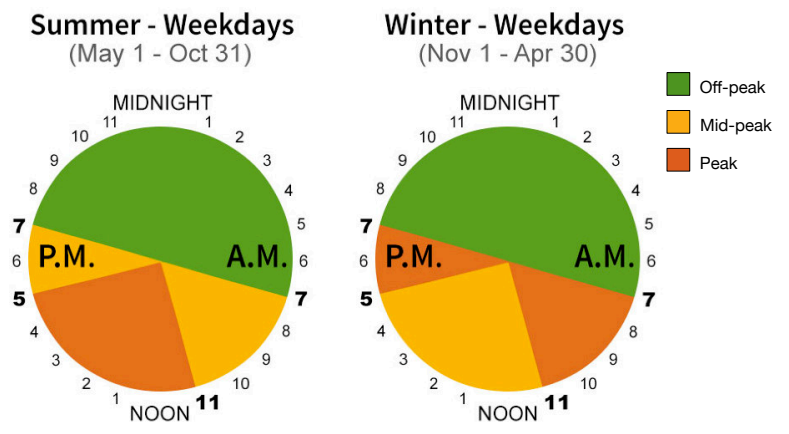

Figure 3. Ontario ToU Pricing

\begin{tabular}{l|c|c}
\hline Energy Usage Tier & $\begin{array}{l}\text { Summer } \\
\text { price } / \mathrm{kWh}\end{array}$ & $\begin{array}{l}\text { Winter } \\
\text { price } / \mathrm{kWh}\end{array}$ \\
\hline 1: $0-500 \mathrm{kWh}$ & $\$ 0.081$ & $\$ 0.066$ \\
2: $501-1000 \mathrm{kWh}$ & $\$ 0.128$ & $\$ 0.104$ \\
3: $1001-1500 \mathrm{kWh}$ & $\$ 0.139$ & $\$ 0.12$ \\
4: $1501-2500 \mathrm{kWh}$ & $\$ 0.158$ & $\$ 0.132$ \\
5: $>2500 \mathrm{kWh}$ & $\$ 0.162$ & $\$ 0.144$ \\
\hline
\end{tabular}

Table 3. Austin Energy 5-Tier Pricing 
where the grid pricing scheme is not a flat rate, the average of the ToU period prices and monthly tiered prices is used. In Ontario and Germany, we expect the trend of increasing prices to continue for the next 20 years. In Austin, where grid prices have been decreasing, the assumed decline of prices is limited to the LCOE of Texas which was calculated to be approximately $\$ 0.10 / \mathrm{kWh}[45,46]$. We realize that our conclusions are sensitive to the price evolution model that we selected based on historical data. Since the past trends are not always a good predictor for the future, we have open-sourced our model for interested readers to explore different price evolution models as well as other inputs [14].

\section{RESULTS AND POLICY IMPLICATIONS}

In this section, we present the results of solving $P_{1}$ and $P_{2}$ for the three jurisdictions. The results for system ROI and Profit are calculated using $P_{1}$. They are presented in the form of violin plots showing the distribution of ROI and profit, and distinguish between the following three parameters:

1. Battery capacity of the system $(0-5 \mathrm{kWh})$

2. PV panel capacity of the system $(2-10 \mathrm{~kW})$

3. Household load split into low, mid, and high electricity usage brackets according to their total annual consumption. The low-use group includes the bottom $40 \%$ of the households in the data set, the high-use group represents the top $20 \%$, and the mid-use group represents the households in the $40-80 \%$ percent range.

Figures 4, 5, and 6 show results for households in Germany, Southern Ontario, and Austin respectively. Figure 7 shows results for Germany households under a ToU tariff with high prices during the day, and Figure 8 shows results with high ToU prices at night. Figures that show ROI over 20 years have a two horizontal lines at ROI $=0.486$ and 1.653 which representing the ROI that one would get after 20 years if, instead of purchasing a PV-storage system, the same amount of money was invested at respective $2 \%$ (low-risk) or $5 \%$ (mid-risk) interest rates (after inflation).

The system sizing problem $P_{2}$ is solved for varying battery prices for each jurisdiction. The results showing the percentage of households where the Profit of the system is maximized with a non-zero battery size as a function of the battery price are presented in Figure 9.

We analyze multiple jurisdictions in order to understand how the differences between them affect the viability of PV-storage systems as an economic investment. We discuss next the observations and insights from each case study, and their implications.

\subsection{General Observations}

All jurisdictions show the trend that increasing the PV capacity of the system also increases the Profit but does not necessarily increase the ROI. This means that PV panels of up to $10 \mathrm{~kW}$ capacity are always profitable, but smaller installations are the best investments. The battery size does not exhibit this effect; in some jurisdictions the ROI is maximized when the system has a non-zero battery size.

The ROI exhibits a trend based on the electricity consumption of the household, with higher consumption typically resulting in a higher ROI. This can be explained by the fact that more load means more opportunity for the system to save money (i.e., make smaller net payments to the utility), and other studies have shown similar results [21].

The comparisons between the ROI results and the lines corresponding to the interest rate show that a PV-Storage system is often more profitable than a $2 \%$ interest rate and rarely more profitable than a $5 \%$ interest rate. 


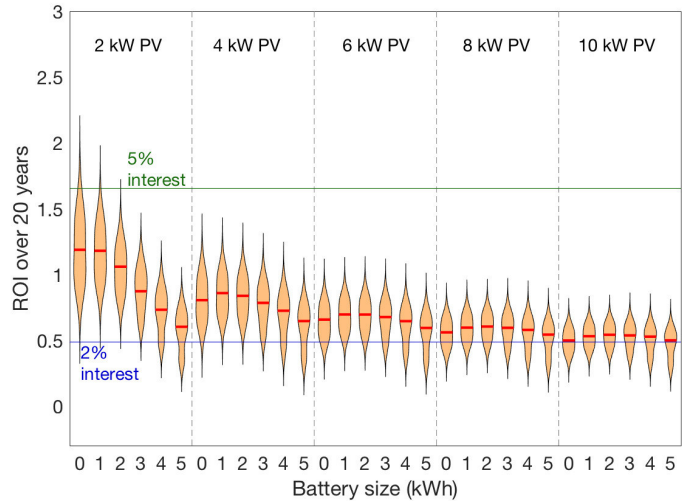

(a) Low-consumption households.

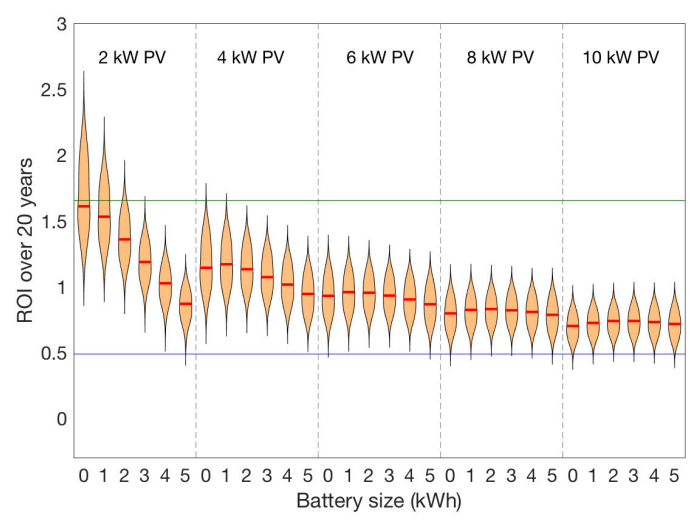

(c) Mid-consumption households.

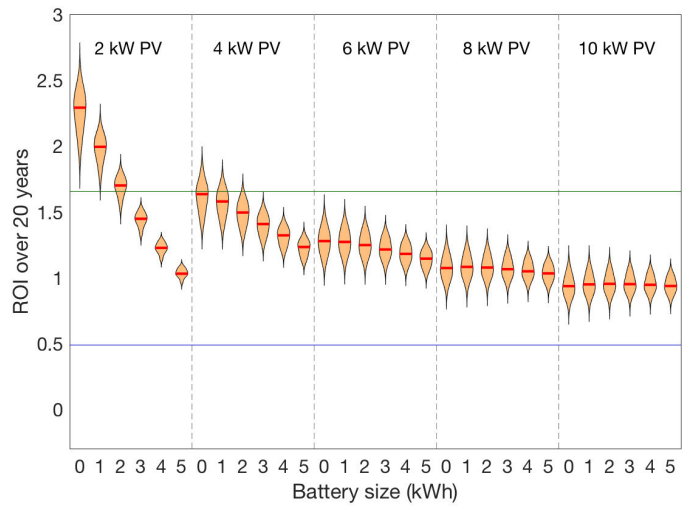

(e) High-consumption households.

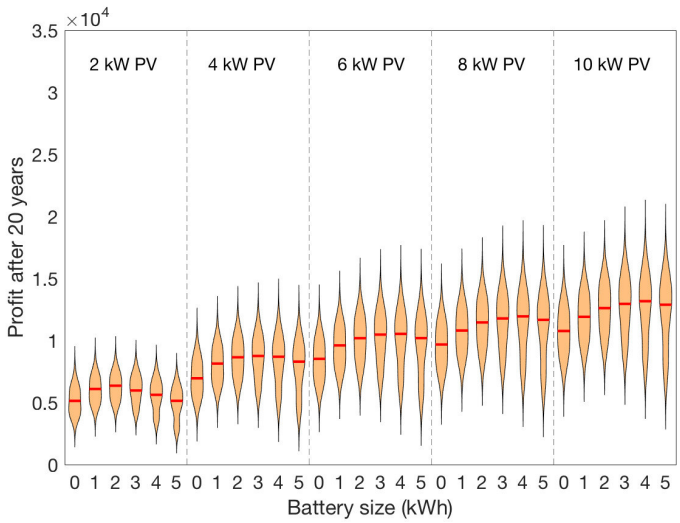

(b) Low-consumption households.

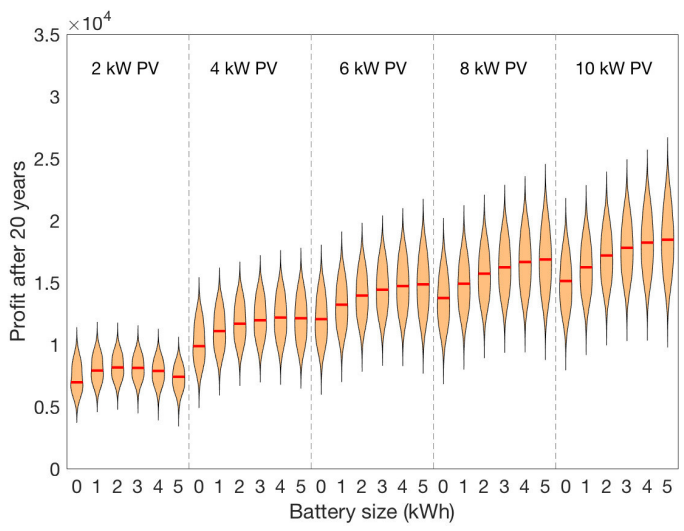

(d) Mid-consumption households.

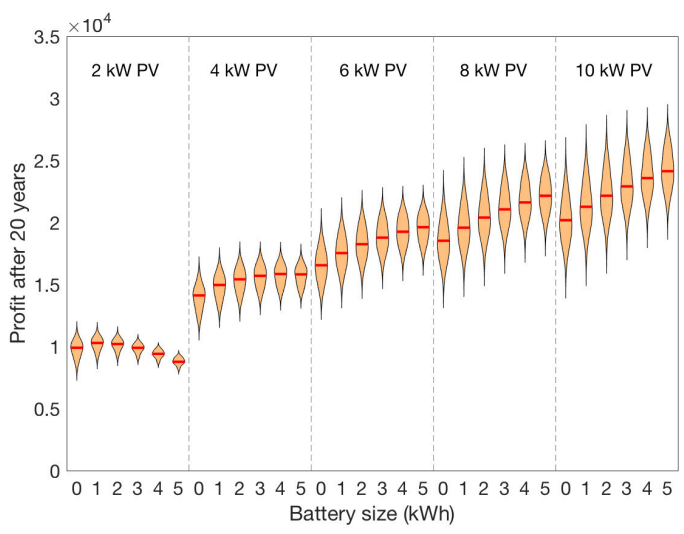

(f) High-consumption households.

Figure 4. Germany households

\subsection{Germany}

The ROI in Germany is high, with small PV-only systems seeing a return of up to $250 \%$ over the 20 year lifetime of the system (corresponding to a compound annual rate of interest of nearly 6.5\%). The battery is used to store excess PV power and use it later, rather than selling it at the low FIT rate. For high-use households with small PV systems (left side of Figures 4e, 4f), there is very little excess PV generation and hence a lower ROI and declining Profit are seen for larger battery sizes. 


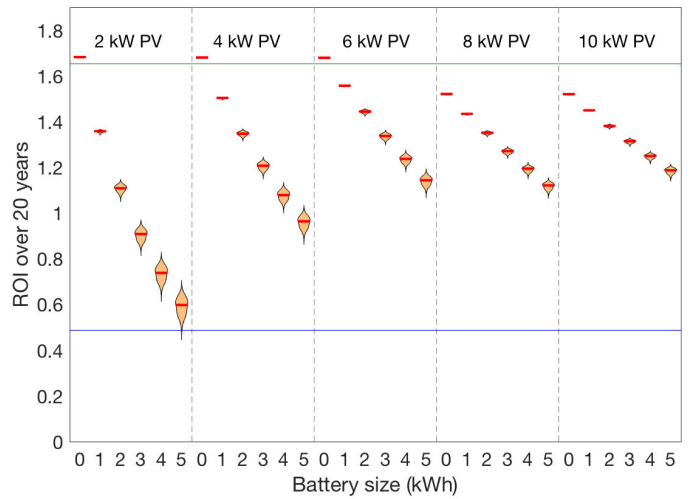

(a) Low-consumption households.

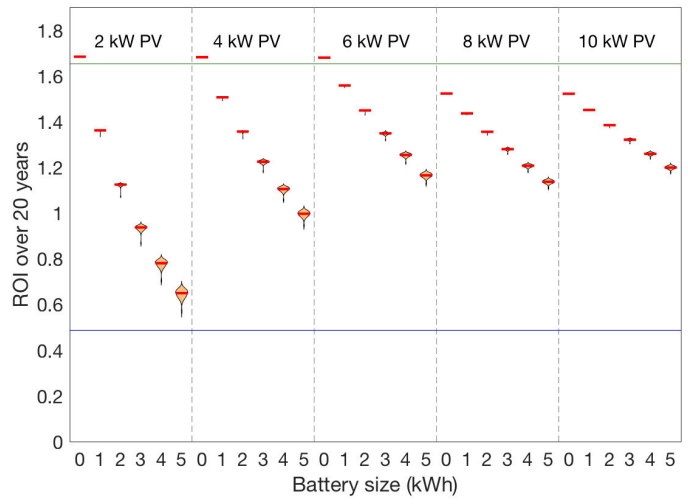

(c) Mid-consumption households.

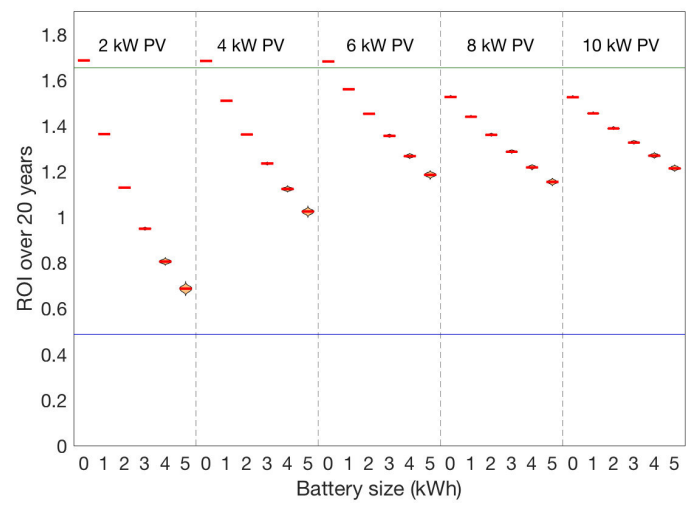

(e) High-consumption households.

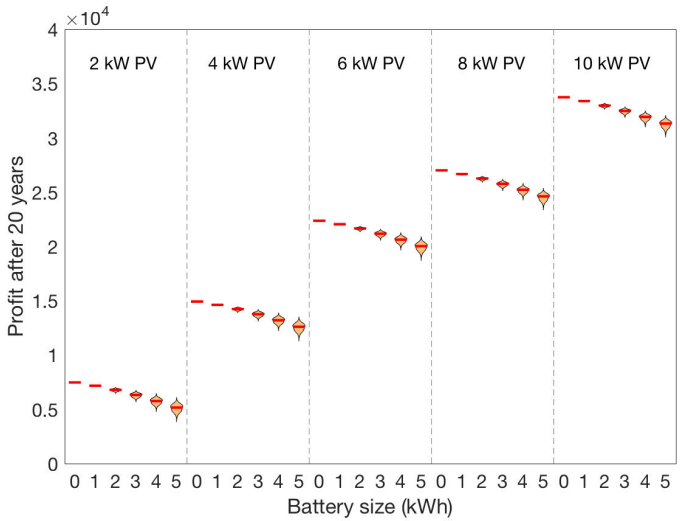

(b) Low-consumption households.

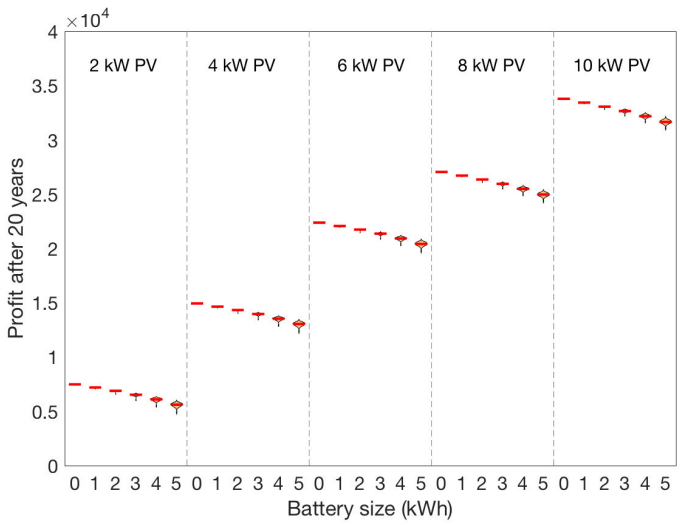

(d) Mid-consumption households.

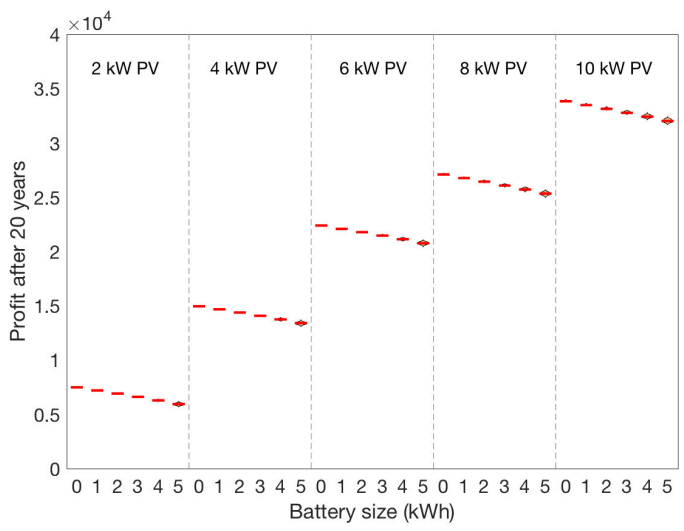

(f) High-consumption households.

Figure 5. Ontario households

For every combination of PV and battery sizes that we have tested, the ROI is higher for high-use households because higher loads result in more power used to offset the high grid price that would normally be paid. High-use households also see an increasing Profit as the battery size goes up to $5 \mathrm{kWh}$ when paired with a $4+\mathrm{kW}$ PV installation, while low-use households see a maximized Profit for lower battery sizes. Systems with $8-10 \mathrm{~kW}$ of PV have a similar ROI with any battery with capacity in the $[0-5] \mathrm{kWh}$ range. 


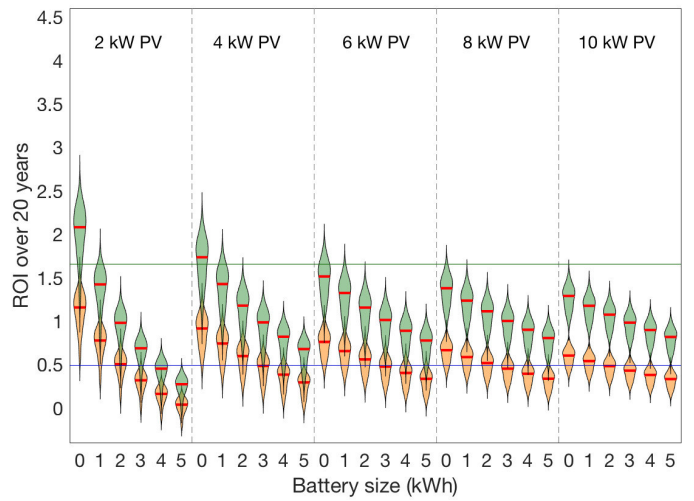

(a) Low-consumption households.

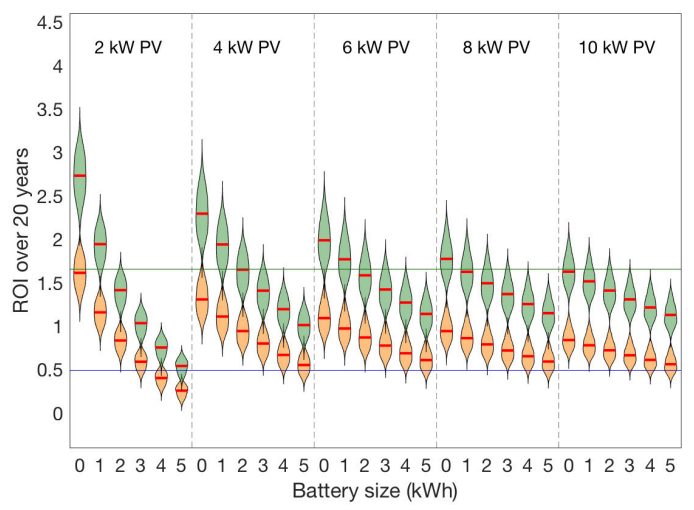

(c) Mid-consumption households.

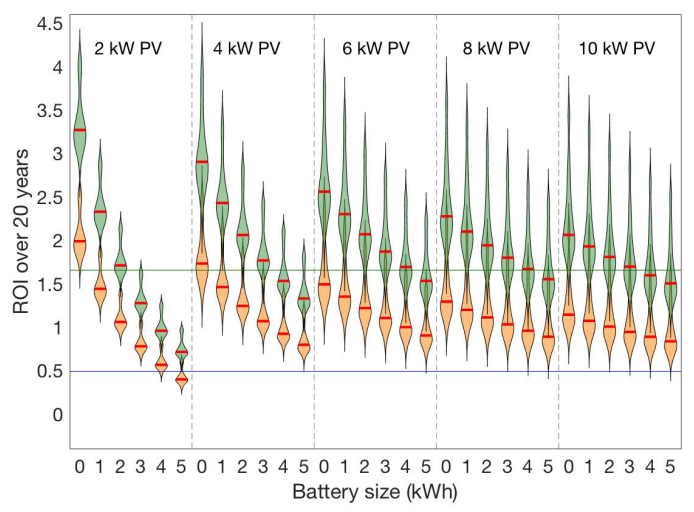

(e) High-consumption households.

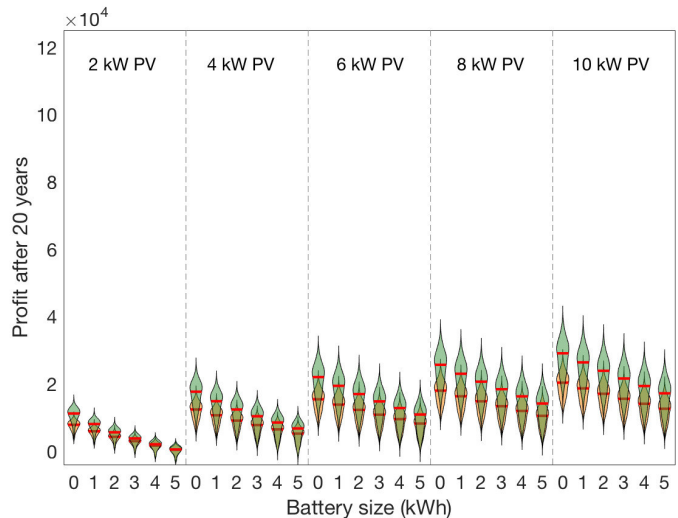

(b) Low-consumption households.

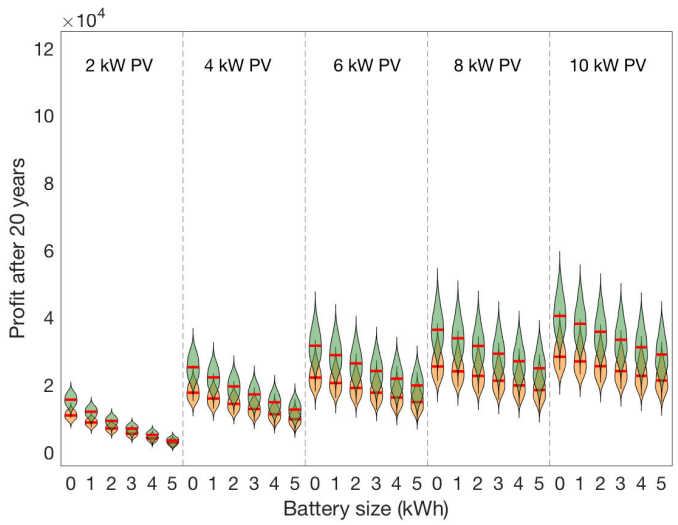

(d) Mid-consumption households.

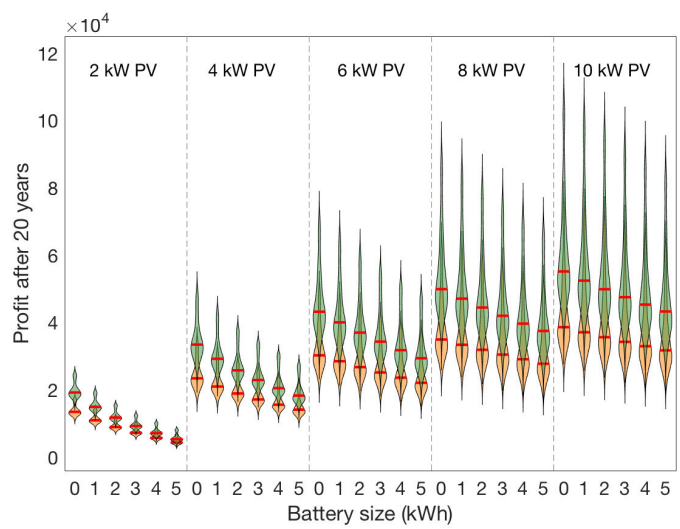

(f) High-consumption households.

Figure 6. Austin households: green distributions show the profitability when the PV panel cost is subsidized by $30 \%$, while yellow distributions are without any subsidies.

\subsection{Ontario}

The ROI for PV systems in Ontario is quite high, but batteries are not a profitable investment. The ROI is almost the same for low, mid, and high-use households across all system dimensions, showing that the load has very little effect on the Profit and ROI. The high FIT rates mean that the optimal control strategy is to sell all PV power and pay the lower grid rates to meet the load. The battery is able to manage the load to avoid using the grid during peak ToU periods, but the savings from 


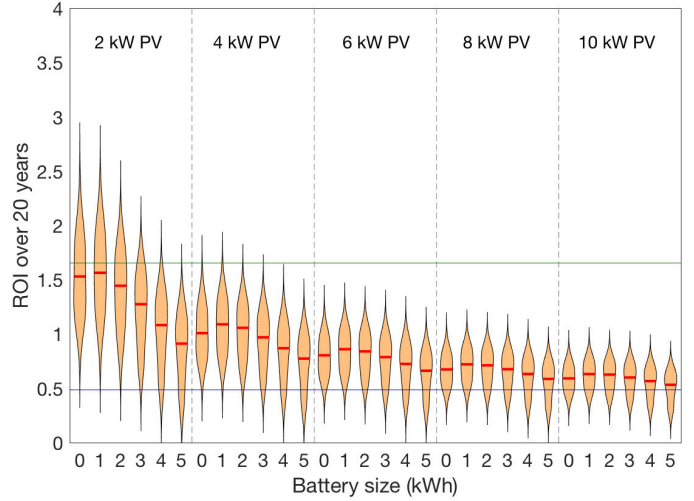

(a) Low-consumption households.

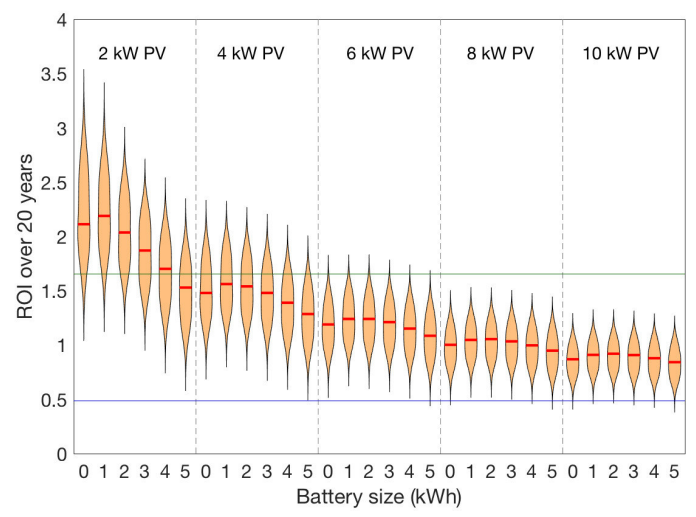

(c) Mid-consumption households.

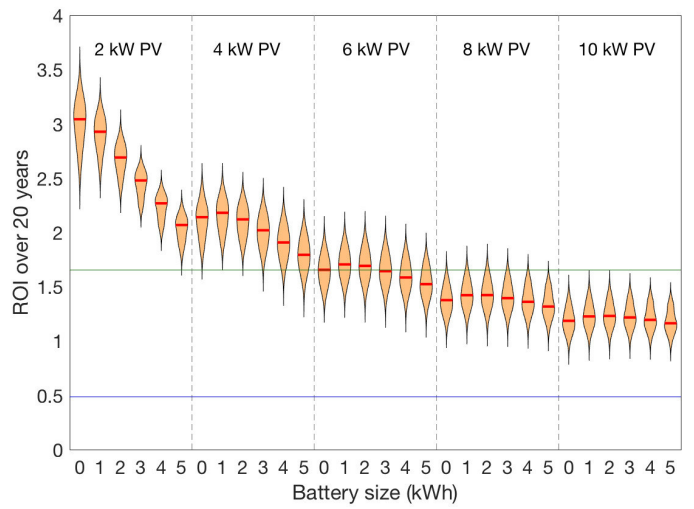

(e) High-consumption households.

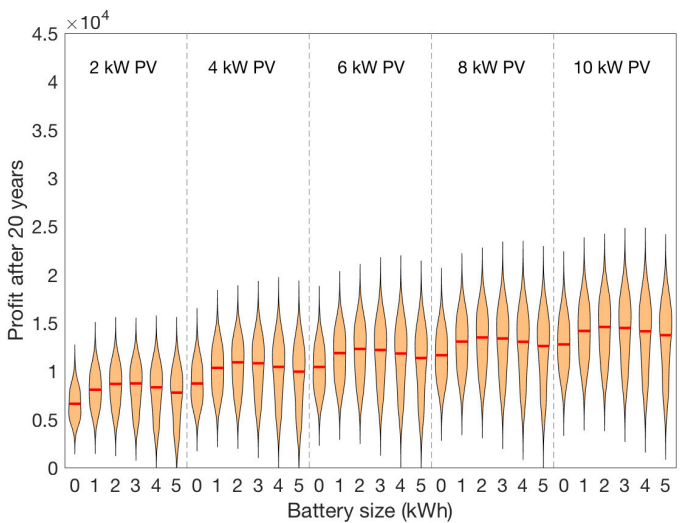

(b) Low-consumption households.

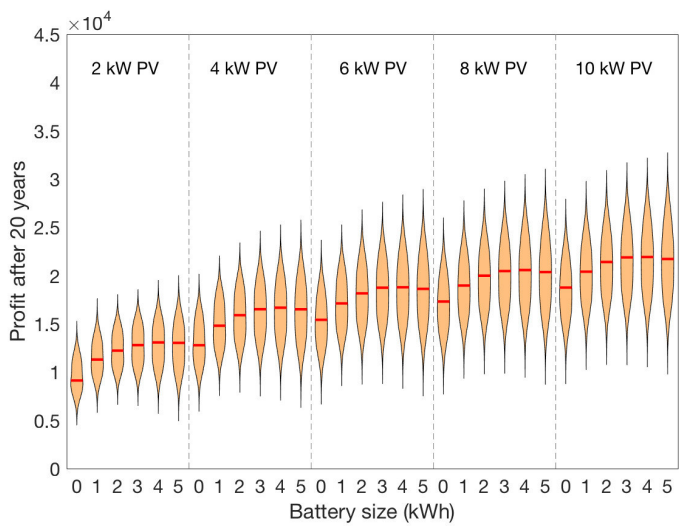

(d) Mid-consumption households.

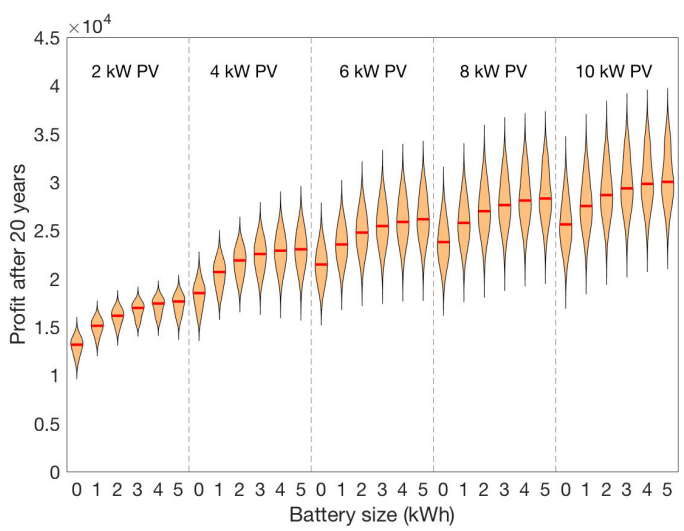

(f) High-consumption households.

Figure 7. Germany households with ToU pricing scheme: high price during the day, low price at night.

this use of the battery are not high enough to cover the battery cost; this is reflected in the lower Profit from systems with batteries compared to PV-only systems.

\subsection{Austin}

In Austin, we see that the largest variation of ROI with respect to the household load. This is largely because high-use households pay much more than low-use households per $\mathrm{kWh}$ consumed as a result of the monthly tiered grid pricing 


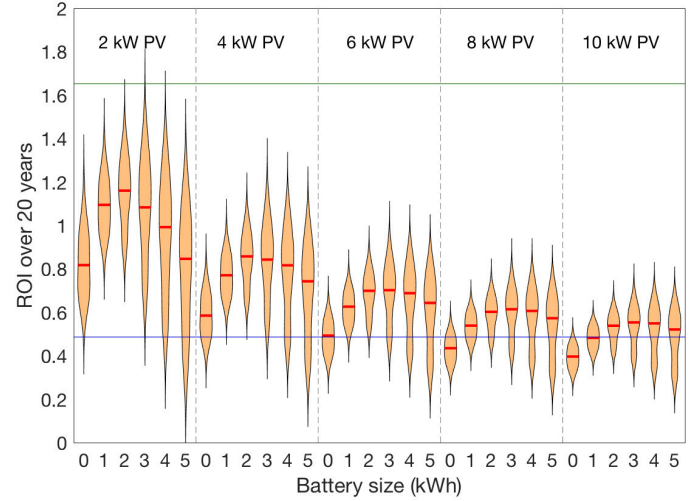

(a) Low-consumption households.

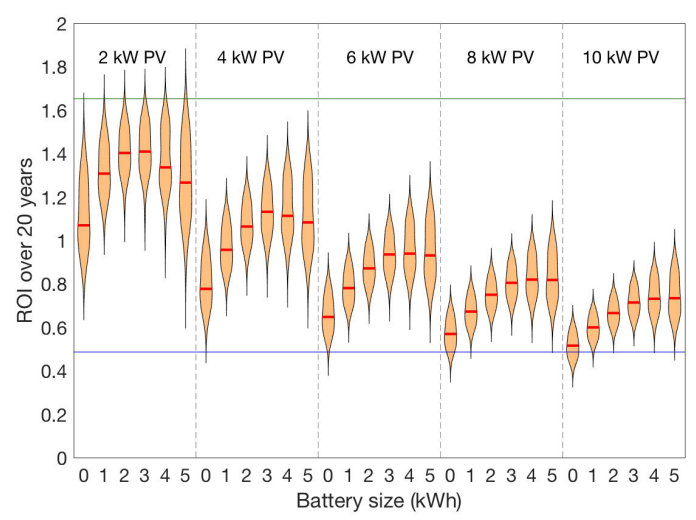

(c) Mid-consumption households.

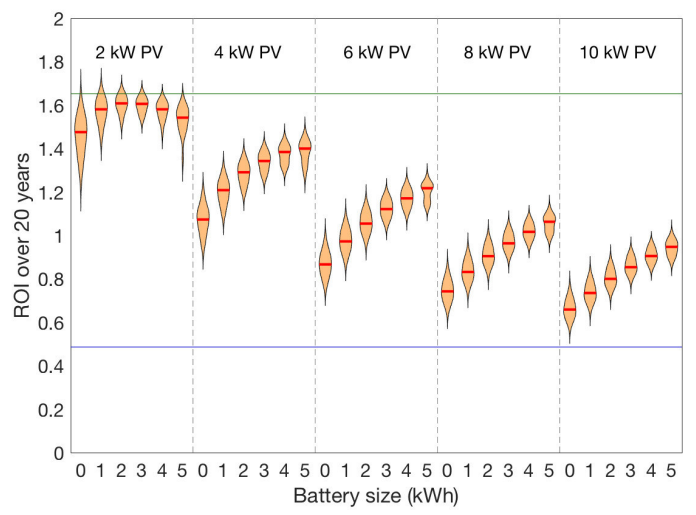

(e) High-consumption households.

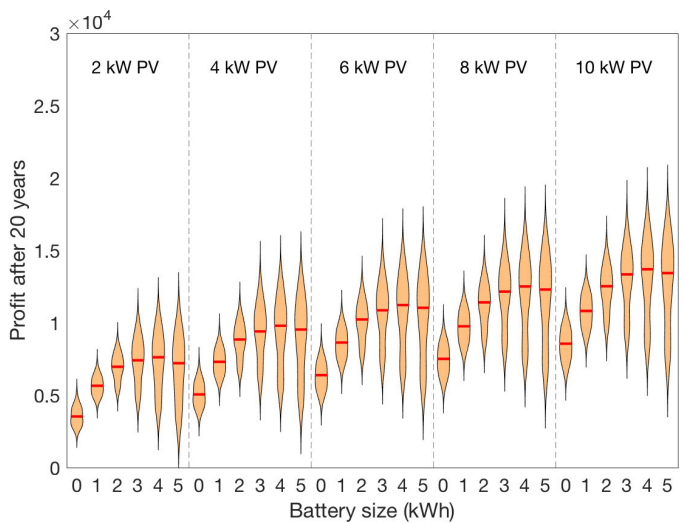

(b) Low-consumption households.

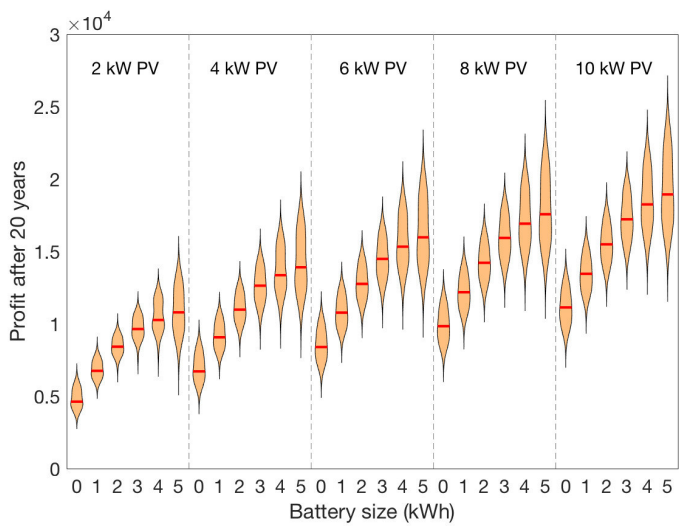

(d) Mid-consumption households.

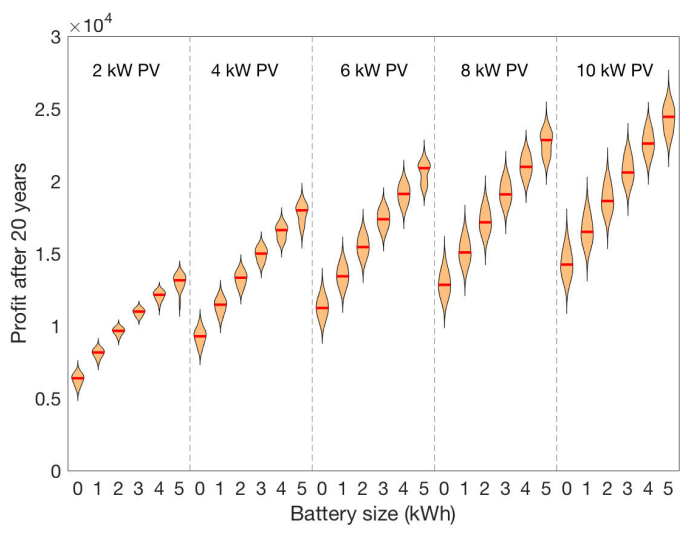

(f) High-consumption households.

Figure 8. Germany households with ToU pricing scheme: high price at night, low price during the day.

scheme. PV panels are able to significantly decrease the amount of grid power that is consumed, meaning that the higher grid price tiers can be avoided; this is especially true during the summer when PV panel generation is higher and electricity prices are also higher. High-use households benefit greatly from avoiding the higher price tiers, and have the highest ROI of the three jurisdictions we analyze. Low-use households are already in the lower price tiers and hence have a much lower ROI.

The battery sees little use in the first years of operation since the price of electricity is low and the pricing scheme does not 


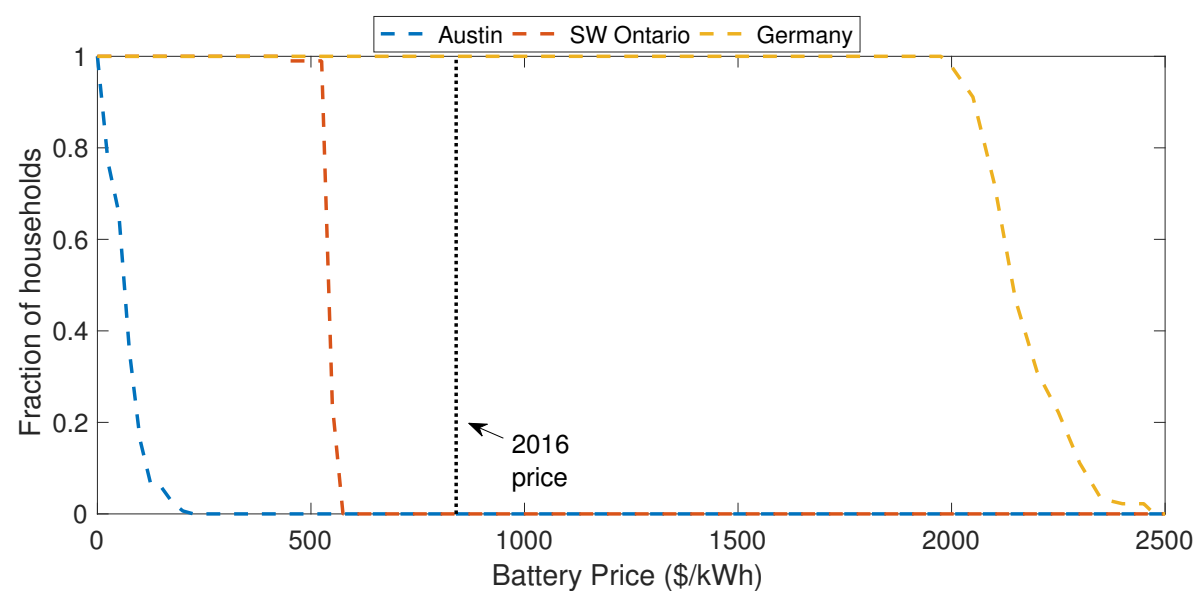

Figure 9. Fraction of households with non-zero optimal battery size as a function of the battery price.

allow for any interesting load management. We model the grid price to hold its value and FIT to lose its value over time, so eventually the FIT is low enough for the optimal system operating strategy to focus on self-consumption of PV, just like in Germany. Contrary to what we see in Germany, the grid and FIT rates provide low margins for savings and are not enough to make the battery a profitable investment regardless of the household load.

The effect of the $30 \%$ subsidy on PV panel costs (green in Figure 6) is a clear increase in the ROI, which provides a strong incentive for large PV installations by bringing their ROI well above the $2 \%$ bank investment rate. Note that in the light of the analysis in Reference [17], these subsidies may be lowered or abolished in the future.

\subsection{Germany with ToU pricing}

There has been discussion recently on potentially deploying ToU pricing in Germany to incentivize load shifting to match variable renewable supply. A higher ToU price during the day favours wind energy, which is mostly prevalent at night, and a higher ToU price by night incentivizes the use of grid-scale solar energy. We consider the potential impact of both ToU schemes, one with peak prices during the day $\left(\mathrm{ToU}_{1}\right)$ and one with peak prices during the night $\left(\mathrm{ToU}_{2}\right)$. With the $\mathrm{ToU}_{1}$ scheme we see a higher ROI compared to the case with flat prices discussed in Section 5.2, while the $\mathrm{ToU}_{2}$ scheme results in a lower ROI.

Both schemes provide an incentive to use batteries for load shifting, and this additional use of the system makes larger batteries more profitable. With the ToU $\mathrm{U}_{1}$ scheme, the power generated by PV panels during the day are able to meet the load and avoid the purchase of grid power during the peak price period. The battery is used to store energy that is purchased at low prices from the grid at night and use it to meet the load that has not been met by PV power during the day. With the $\mathrm{ToU}_{2}$ scheme, there is a strong incentive to store PV power to use at night when prices are high. Large PV systems generate a lot of energy and require large batteries to store this energy for consumption at night. As a result, low-use households maximize their ROI with a 2-3 kWh battery (see Figure 8a), while high-use households have a maximum ROI with a larger battery (see Figure 8e) especially when the PV panel capacity is $6 \mathrm{~kW}$ or more.

\subsection{Sensitivity to Battery Price}

To characterize the effect of battery price on the profitability of batteries in multiple jurisdictions, we solve the system sizing optimization problem $P_{2}$ for each jurisdiction. We found that the Profit was maximized when the size of PV panels is equal to $P V_{\max }$, which was set to $10 \mathrm{~kW}$. The results are presented in Figure 9 and show how the price at which batteries achieve profitability (for some fraction of the households) differs across the jurisdictions. 
In Germany, batteries are profitable even at very high prices, with all households having a non-zero optimal battery size at $\$ 2000 / \mathrm{kWh}$ over 20 years when combined with a $10 \mathrm{~kW} \mathrm{PV}$ installation. Some households can tolerate a cost of even $\$ 2500 / \mathrm{kWh}$. In Ontario, the use-case for batteries is to take advantage of ToU pricing via load shifting; this application becomes economically viable only at $\$ 525 / \mathrm{kWh}$ over 20 years. In Austin, batteries have to be very cheap for them to be economically viable, with some households needing a battery that is almost free in order to make any kind of profit.

\subsection{Policy Implications}

We take the position of a policy maker that is trying to incentivize the adoption of PV-Storage systems. Storage is able to provide resilience to power failure, increase self-consumption of local PV generation, and automate load shifting which can save on energy costs for both consumers and the utility [12]. In our analysis, policy makers can influence the profitability, and therefore the adoption of PV-storage systems, by setting any combination of the following three attributes [7]: 1) the value of FIT, 2) the pricing scheme for grid electricity, and 3) up-front subsidies to offset system capex.

FIT was initially deployed as a short-term solution to incentivize the purchase of PV panels by guaranteeing a long-term source of revenue. The FIT rate has been declining as the cost of PV panels has declined. Our results show that high FIT prices incentivize the adoption of PV-only systems for the purpose of selling PV power to the grid, rather than storage. Conversely, a low FIT (especially a FIT lower than the price of grid electricity) would incentivize self-consumption and therefore the adoption of energy storage.

The grid pricing scheme can be also structured in a way that promotes the adoption of batteries. Ontario adopted ToU pricing in 2006 for the purpose of allowing both utilities and consumers to benefit from load shifting [4]. Many consumers have not significantly changed their electricity usage patterns because, even with a 2:1 ratio of peak to off-peak price, the margin for savings is small because of the low electricity prices and is not worth the effort [32]. A battery can be automated to take advantage of even small margins to save money without any change in user consumption patterns. This is shown in our analysis of Germany with ToU pricing, compared to the existing case with flat pricing. A ToU scheme with peak-prices during the day incentivizes both PV and storage adoption, while peak-prices at night provides an incentive to purchase larger storage capacity.

Subsidizing the upfront cost of PV-battery systems has significant effect on their adoption. For example, the $30 \%$ USA federal tax subsidy for PV panels increases ROI significantly in Texas. Subsidies for storage systems can incentivize their adoption, but the size of the subsidy necessary to make the system profitable is dependent on the jurisdiction. For example, in Ontario, storage systems become profitable only when the cost is lower than $\$ 525 / \mathrm{kWh}$; with today's prices, a subsidy of $\$ 315 / \mathrm{kWh}$, which is $60 \%$ of the cost of a Tesla Powerwall 2 , is needed to make storage systems profitable ${ }^{6}$. In Texas, a subsidy is not enough to make storage systems profitable unless it covers almost the entire cost; it is clear that an additional policy, such as the introduction of a pricing scheme that provides an incentive for load shifting, is needed for storage systems to be economically viable in this jurisdiction.

\subsection{Limitations}

We see four main limitations of our work. First, our analysis is based on 20-year projections of various quantities, including the price of grid electricity, and the cost of storage systems. Of course, our conclusions are limited by the accuracy of these projections. Nevertheless, because we study sensitivity to a wide range of system sizes and parameters, we believe that our insights are relatively insensitive to the actual values of these price forecasts, and still offer concrete suggestions to policy makers.

Second, to keep modeling tractable, we have ignored the fact that, in each jurisdiction, consumers have the choice of many

\footnotetext{
${ }^{6}$ This calculation assume that only the first storage purchase, covering the first 10 years of system lifetime, is subsidized. The replacement at the 10 -year mark, projected to cost $60 \%$ of the current price, is not subsidized.
} 
pricing and financing options. Again, although the actual financing option chosen by a residential customer would affect long-term profitability, we believe that our overall conclusions are accurate at least to first order.

Third, we calculate the ROI assuming best-possible (offline optimal) operation of the system as computed by the ILP, which is not always achievable in a real system deployment. Existing work on topic of PV-storage system operation [22,51] shows that the gap between optimal operation and the best practical online operation algorithms is small, and hence we believe that ROI with optimal system operation is a good indicator of what can be achieved in practice.

Finally, again to keep the problem tractable, we have not considered the full range of policy choices available to decision makers. Instead, we analyze well-known and widely-used policy alternatives (such as using Time-of-Use pricing in Germany). Using our work as the basis for a more extensive analysis of other policies to encourage prosumers is a rich vein for future work.

\section{CONCLUSIONS}

We observe that policy makers in many jurisdictions have implemented various incentive schemes to encourage consumers to become prosumers. The mixed success of these polices can be explained by differences in jurisdiction-specific parameters such as solar radiation profile, the typical residential loads, the cost of system components, the price of grid electricity, and incentive programs on PV and storage system adoption. We study the role of jurisdictions in affecting profitability by analyzing three distinct jurisdictions: Germany, Ontario, and Austin, Texas. In each jurisdiction, for a range of PV and storage system sizes, we compute the optimal use of the system, and hence the best possible profitability of that system in that jurisdiction over a 20 year life span. We find not only the expected impact of jurisdiction on adoption but also that policy makers can use the price of grid electricity as well as upfront subsidies to influence adoption.

\section{ACKNOWLEDGMENTS}

The authors acknowledge Adedamola Adepetu for his assistance in data acquisition and helpful discussion.

\section{REFERENCES}

1. Austin energy residential rates. http://austinenergy.com. Accessed: 2016-09-20.

2. Fit/microfit price schedule. http://microfit.powerauthority.on.ca/sites/default/files/version4/ FIT-Price-Schedule-2016-06-21.pdf. Accessed: 2016-09-20.

3. Ontario electricity prices. http://www.ontarioenergyboard.ca/OEB/Consumers/Electricity/Electricity+ Prices. Accessed: 2016-09-20.

4. Smart meters and time-of-use prices. http://www.energy.gov.on.ca/en/smart-meters-and-tou-prices/. Accessed: 2017-02-14.

5. What german households pay for power. https://www.cleanenergywire.org/factsheets/ what-german-households-pay-power. Accessed: 2016-09-20.

6. Pecan Street Inc. Dataport, 2016.

7. A. Adepetu and S. Keshav. Understanding solar PV and battery adoption in ontario: An agent-based approach. In Proceedings of the Seventh International Conference on Future Energy Systems, e-Energy '16, pages 5:1-5:12, New York, NY, USA, 2016. ACM.

8. V. Bertsch, J. Geldermann, and T. Lühn. What drives the profitability of household pv investments, self-consumption and self-sufficiency? 2017.

9. N. Blair, A. Dobos, J. Freeman, T. Neises, M. Wagner, T. Ferguson, P. Gilman, and S. Janzou. System advisor model, sam 2014.1. 14: General description. Nat. Renew. Energy Lab., Denver, CO, USA, Tech. Rep. NREL/TP-6A20-61019, 2014. 
10. G. de Oliveira e Silva and P. Hendrick. Lead-acid batteries coupled with photovoltaics for increased electricity selfsufficiency in households. Applied Energy, 178:856 - 867, 2016.

11. R. Dufo-López. Optimisation of size and control of grid-connected storage under real time electricity pricing conditions. Applied Energy, 140:395 - 408, 2015.

12. M. Dyson, J. Mandel, et al. The economics of demand flexibility: How "flexiwatts" create quantifiable value for customers and the grid. Rocky Mountain Institute, August, 2015.

13. O. Erdinc, N. G. Paterakis, I. N. Pappi, A. G. Bakirtzis, and J. P. C. ao. A new perspective for sizing of distributed generation and energy storage for smart households under demand response. Applied Energy, 143:26 - 37, 2015.

14. Fiodar Kazhamiaka. Jurisdiction-based profitability optimization model repository. https://github.com/iss4e/ jurisdiction-profitability.git, 2017.

15. R. Fourer, D. M. Gay, and B. Kernighan. Ampl, volume 117. Boyd \& Fraser Danvers, MA, 1993.

16. German Solar Association. Statistische zahlen der deutschen solarstrombranche (photovoltaik), 2014. Accessed: 2016$12-24$.

17. A. Goodrich, T. James, and M. Woodhouse. Residential, commercial, and utility-scale photovoltaic (pv) system prices in the united states: current drivers and cost-reduction opportunities. Technical report, National Renewable Energy Laboratory (NREL), Golden, CO., 2012.

18. G. Graditi, M. Ippolito, E. Telaretti, and G. Zizzo. Technical and economical assessment of distributed electrochemical storages for load shifting applications: An italian case study. Renewable and Sustainable Energy Reviews, 57:515-523, 2016.

19. P. Grünewald, E. McKenna, and M. Thomson. Keep it simple: time-of-use tariffs in high-wind scenarios. IET Renewable Power Generation, 9(2):176-183, 2015.

20. A. Johann and R. Madlener. Profitability of energy storage for raising self-consumption of solar power: Analysis of different household types in germany. Energy Procedia, 61:2206-2210, 2014.

21. T. Kaschub, P. Jochem, and W. Fichtner. Solar energy storage in german households: profitability, load changes and flexibility. Energy Policy, 98:520 - 532, 2016.

22. F. Kazhamiaka, C. Rosenberg, and S. Keshav. Practical strategies for storage operation in energy systems: design and evaluation. IEEE Transactions on Sustainable Energy, 7(4):1602-1610, 2016.

23. F. Kazhamiaka, C. Rosenberg, S. Keshav, and K.-H. Pettinger. Li-ion storage models for energy system optimization: The accuracy-tractability tradeoff. In Proceedings of the Seventh International Conference on Future Energy Systems. ACM, 2016.

24. L. Kools and F. Phillipson. Data granularity and the optimal planning of distributed generation. Energy, 112:342-352, 2016.

25. P. Layer. Aktueller Stand der Forschung, pages 13-28. Springer Fachmedien Wiesbaden, Wiesbaden, 2017.

26. J. Li and M. A. Danzer. Optimal charge control strategies for stationary photovoltaic battery systems. Journal of Power Sources, 258:365 - 373, 2014.

27. J. Linssen, P. Stenzel, and J. Fleer. Techno-economic analysis of photovoltaic battery systems and the influence of different consumer load profiles. Applied Energy, 185, Part 2:2019 - 2025, 2017. Clean, Efficient and Affordable Energy for a Sustainable Future. 
28. G. Lorenzi and C. A. S. Silva. Comparing demand response and battery storage to optimize self-consumption in PV systems. Applied Energy, 180:524 - 535, 2016.

29. R. Luthander, J. Widén, D. Nilsson, and J. Palm. Photovoltaic self-consumption in buildings: A review. Applied Energy, 142:80 - 94, 2015.

30. A. Malhotra, B. Battke, M. Beuse, A. Stephan, and T. Schmidt. Use cases for stationary battery technologies: A review of the literature and existing projects. Renewable and Sustainable Energy Reviews, 56:705 - 721, 2016.

31. G. Merei, J. Moshövel, D. Magnor, and D. U. Sauer. Optimization of self-consumption and techno-economic analysis of PV-battery systems in commercial applications. Applied Energy, 168:171 - 178, 2016.

32. G. R. Newsham and B. G. Bowker. The effect of utility time-varying pricing and load control strategies on residential summer peak electricity use: a review. Energy policy, 38(7):3289-3296, 2010.

33. A. Nicholls, R. Sharma, and T. Saha. Financial and environmental analysis of rooftop photovoltaic installations with battery storage in australia. Applied Energy, 159:252 - 264, 2015.

34. B. Nykvist and M. Nilsson. Rapidly falling costs of battery packs for electric vehicles. Nature Climate Change, 5(4):329332, 2015.

35. D. Parra and M. K. Patel. Effect of tariffs on the performance and economic benefits of PV-coupled battery systems. Applied Energy, 164:175 - 187, 2016.

36. S. Quoilin, K. Kavvadias, A. Mercier, I. Pappone, and A. Zucker. Quantifying self-consumption linked to solar home battery systems: Statistical analysis and economic assessment. Applied Energy, 182:58 - 67, 2016.

37. K. R. Rábago, L. Libby, and T. Harvey. Designing austin energy's solar tariff using a distributed PV value calculator. In Proceedings of World Renewable Energy Forum, 2012.

38. E. L. Ratnam, S. R. Weller, and C. M. Kellett. An optimization-based approach to scheduling residential battery storage with solar PV: Assessing customer benefit. Renewable Energy, 75:123 - 134, 2015.

39. Z. Ren, G. Grozev, and A. Higgins. Modelling impact of PV battery systems on energy consumption and bill savings of australian houses under alternative tariff structures. Renewable Energy, 89:317 - 330, 2016.

40. Solacity. Ontario microfit installation cost. http://www. solacity.com/microfit, 2016. Accessed: 2016-11-25.

41. M. Taylor, J. McLaren, K. Cory, T. Davidovich, J. Sterling, and M. Makhyoun. Value of solar: Program design and implementation considerations. National Renewable Energy Laboratory, 2015.

42. E. Telaretti, G. Graditi, M. Ippolito, and G. Zizzo. Economic feasibility of stationary electrochemical storages for electric bill management applications: The italian scenario. Energy Policy, 94:126 - 137, 2016.

43. Tesla corp. Powerwall 2. https ://www .tesla. com/powerwall, 2016. Accessed: 2016-11-25.

44. US Department of Energy. Residential Renewable Energy Tax Credit. https://energy.gov/savings/ residential-renewable-energy-tax-credit, 2016. Accessed: 2016-11-25.

45. U.S. Energy Information Administration. EIA-923, power plant operations report. https://www.eia.gov/ electricity/state/texas, 2016. Accessed: 2017-01-25.

46. U.S. Energy Information Administration. US LCOE ( $\$ / \mathrm{kWh})$ EIA prognosis for 2020. http://www. eia.gov/ forecasts/aeo/electricity_generation.cfm, 2016. Accessed: 2017-01-25.

47. J. Weniger, T. Tjaden, and V. Quaschning. Sizing of residential pv battery systems. Energy Procedia, 46:78-87, 2014. 
48. William Steel, Renewable Energy World. Sweden Set to Launch Residential Energy Storage Scheme. http://www.renewableenergyworld.com/articles/2016/10/ sweden-set-to-launch-residential-energy-storage-scheme.html, 2016. Accessed: 2016-11-25.

49. H. Wirth and K. Schneider. Recent facts about photovoltaics in germany. Fraunhofer ISE, page 92, 2017.

50. A. Yoshida, T. Sato, Y. Amano, and K. Ito. Impact of electric battery degradation on cost- and energy-saving characteristics of a residential photovoltaic system. Energy and Buildings, 124:265 - 272, 2016.

51. T. Zhu, A. Mishra, D. Irwin, N. Sharma, P. Shenoy, and D. Towsley. The case for efficient renewable energy management in smart homes. In Proceedings of the Third ACM Workshop on Embedded Sensing Systems for Energy-Efficiency in Buildings, pages 67-72. ACM, 2011.

52. A. Zucker and T. Hinchliffe. Optimum sizing of PV-attached electricity storage according to power market signals - a case study for germany and italy. Applied Energy, 127:141 - 155, 2014. 